\title{
RANKING INSTITUTIONS WITHIN A UNIVERSITY BASED ON THEIR SCIENTIFIC PERFORMANCE: A PERCENTILE-BASED APPROACH
}

\author{
Clasificación de instituciones dentro de una \\ universidad en función de su rendimiento científico: \\ un enfoque basado en percentiles
}

Nikola Zornic, Lutz Bornmann, Milica Maricic, Aleksandar Markovic, Milan Martic, and Veljko Jeremic

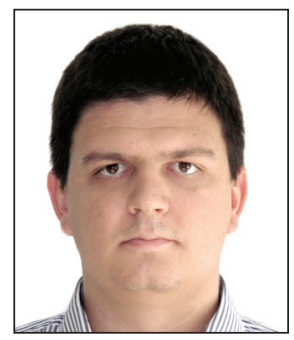

Nikola Zornic is a teaching associate at the Department of Management at the Faculty of Organizational Sciences, University of Belgrade. After graduation in 2013 at the Faculty of Organizational Sciences, he got his MSc at the same Faculty, where he specialized in business intelligence and decision making. In 2014, he enrolled in a post-graduate program at the same Faculty, where he is specializing in business statistics.

http://orcid.org/0000-0002-3597-0627

University of Belgrade, Faculty of Organizational Sciences Jove Ilica 154, 11000 Belgrade, Serbia nikola.zornic@fon.bg.ac.rs

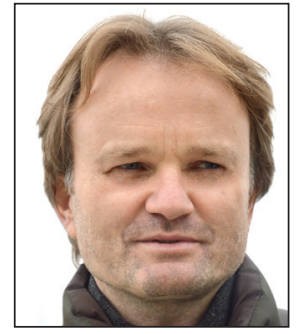

Lutz Bornmann works as a sociologist of science at the Division for Science and Innovation Studies in the Administrative Headquarters of the Max Planck Society. His current research interests include research evaluation, peer review, bibliometrics, and altmetrics. He is a member of the editorial board of the Journal of infometrics, PLoS one, Scientometrics, and Journal of the Association for Information Science and Technology. Since 2004, he has published more than 184 papers in journals covered by Web of Science with a total of more than 2,600 citations.

http://orcid.org/0000-0003-0810-7091

Administrative Headquarters of the Max Planck Society Hofgartenstr. 8, 80539 Munich, Germany bornmann@gv.mpg.de

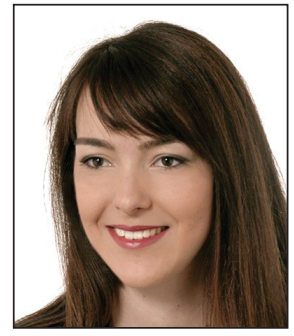

Milica Maricic is a teaching associate at the Department of Operations Research and Statistics at the Faculty of Organizational Sciences, University of Belgrade (UB). After graduation in 2014 at the Faculty of Organizational Sciences, she enrolled in post-graduate studies at the same Faculty, where she is specializing in business statistics. In 2015, she enrolled in a post-graduate program at the $U B$, which is part of the Tempus project Incoming, where she is specializing in social sciences and computing.

http://orcid.org/0000-0003-0441-9899

University of Belgrade, Faculty of Organizational Sciences Jove llica 154, 11000 Belgrade, Serbia milica.maricic@fon.bg.ac.rs

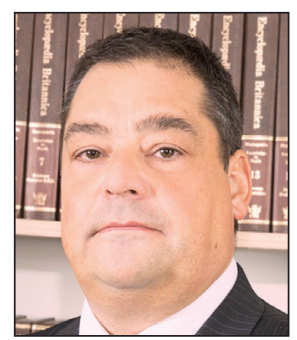

Aleksandar Markovic is a full professor at the Faculty of Organizational Sciences, University of Belgrade, Serbia, where he got his MSc and PhD degrees in business decision making. Areas of his research include business decision making, e-business, and simulation methods.

http://orcid.org/0000-0002-1221-4351

University of Belgrade, Faculty of Organizational Sciences Jove Ilica 154, 11000 Belgrade, Serbia aleksandar.markovic@fon.bg.ac.rs 


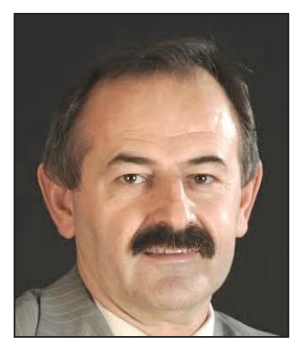

Milan Martic is a dean and full professor at the Department of Operational Research and Statistics at the Faculty of Organizational Sciences, University of Belgrade. He defended his PhD thesis in the field of operational research. He has published over 130 scientific papers with emphasis on $I S I$ indexed journals. He is co-author of seven university textbooks. He has acted as a reviewer for many ISI indexed journals. His major interests are data envelopment analysis, efficiency models, and operational research.

http://orcid.org/0000-0002-0289-6678

University of Belgrade, Faculty of Organizational Sciences Jove llica 154, 11000 Belgrade, Serbia martic.milan@fon.bg.ac.rs

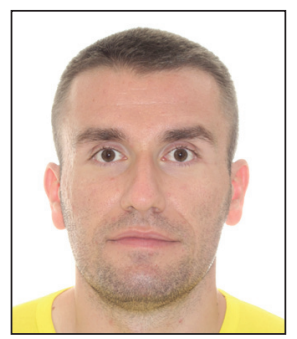

Veljko Jeremic is an assistant professor at the Department of Operational Research and Statistics at the Faculty of Organizational Science, University of Belgrade. He finished his PhD thesis in the field of computational statistics. He has published over 60 scientific papers with emphasis on ISI indexed journals. He is co-author of one university textbook. He has acted as a reviewer for many ISI indexed journals such as Jasist, Scientometrics, and Journal of applied statistics.

http://orcid.org/0000-0002-7761-1841

University of Belgrade, Faculty of Organizational Sciences Jove Ilica 154, 11000 Belgrade, Serbia veljko.jeremic@fon.bg.ac.rs

\begin{abstract}
Over the recent years, the subject of university rankings has attracted a significant amount of attention and sparked a scientific debate. However, few studies on this topic focus on elaborating the scientific performance of universities' institutions, such as institutes, schools, and faculties. For this reason, the aim of this study is to design an appropriate framework for evaluating and ranking institutions within a university. The devised methodology ranks institutions based on the number of published papers, mean normalized citation score (MNCS), and four percentile-based indicators using the I-distance method. We applied the proposed framework and scrutinized the University of Belgrade (UB) as the biggest and the best-ranked university in Serbia. Thus, 31 faculties and 11 institutes were compared. Namely, an in-depth percentile-based analysis of the UB papers indexed in the Science Citation Index Expanded (SCle) and the Social Science Citation Index (SSCl) for the period 2008-2011 is provided. The results clearly show considerable discrepancies in two occasions: first, when it comes to the question of leading author, and second, when it comes to analyzing the percentile rank classes (PRs) of groups of faculties.
\end{abstract}

\title{
Keywords
}

Bibliometrics; Percentile; Percentile rank classes; Scientific productivity; Scientific output; University rankings; Institutes; Schools; Faculties; I-distance.

\section{Resumen}

En los últimos años, el tema de los rankings universitarios ha atraído mucha atención y ha provocado debates científicos. Sin embargo, pocos estudios sobre este tema se centran en la actuación científica de las instituciones de las universidades, como los institutos, escuelas y facultades. Por esta razón, el objetivo de este estudio es diseñar un marco adecuado para la evaluación y clasificación de las instituciones dentro de una universidad. La metodología ideada clasifica las instituciones según el número de trabajos publicados, la puntuación media de citación normalizada (MNCS), y cuatro indicadores basados en percentiles utilizando el método de la I-distancia. Aplicamos el marco propuesto a la Universidad de Belgrado (UB), que es la universidad mayor y mejor clasificada de Serbia. Se compararon 31 facultades y 11 institutos y se proporciona un análisis basado en percentiles de los artículos de la UB indexados en el Science Citation Index Expanded (SCle) y el Social Science Citation Index (SSCI) para el período 2008-2011. Los resultados muestran claramente discrepancias considerables en dos ocasiones: primera, cuando se trata del autor líder, y segunda, cuando se utilizan los tramos de percentil (RP) de grupos de facultades.

\section{Palabras clave}

Bibliometría; Percentiles; Clases de rangos de percentil; Tramos de percentil; Productividad científica; Clasificación universitaria; Ranking universitario; Institutos; Facultades; I-distancia.

Zornic, Nikola; Bornmann, Lutz; Maricic, Milica; Markovic, Aleksandar; Martic, Milan; Jeremic, Veljko (2015). "Ranking institutions within a university based on their scientific performance: A percentile-based approach". El profesional de la información, v. 24, n. 5, pp. 551-566. 


\section{Introduction}

The first global university rankings appeared approximately ten years ago, and since then their popularity and number have significantly increased (Hazelkorn, 2014). One of the reasons for this development is the ability of the rankings to provide an easily understandable, single number which situates a particular university in the global higher education institutions (HEIs) context (Saisana; D'Hombres, 2008). Also, as the results of university ranking methodologies are easily accessible and widely accepted by various stakeholders, they are often used as an indicator of a university's reputation and educational performance (Altbach, 2013; Docampo, 2013; Paruolo; Saisana; Saltelli, 2013). Besides prospective students and their parents, government representatives and politicians seem to be profoundly influenced by ranking lists, as their results have stimulated national debates (Saisana; D’Hombres; Saltelli, 2011; Hazelkorn, 2011; Bornmann, 2013).

Indeed, a country's HEls global competitiveness has gained importance and consequently, countries strive to achieve respectful positions in university rankings. Therefore, worldwide universities are, besides going through restructuring processes, expecting their academic staff to increase publishing in refereed journals (McGrail; Rickard; Jones, 2006) in order to advance in the rankings. The turn towards "world-class" higher education resulted in a paradigm shift in academic governance (Chou; Lin; Chiu, 2013). Direct implications of this change are reflected through the application of the "publish or perish" approach for academic staff. Survival and success in the academic world depend on the number of publications (Frey, 2003). The academic staff in developing countries is particularly affected as they have to achieve competitive results with scarce funds. For example, the University of Belgrade (UB) has tightened its criteria for obtaining university positions (Assistant, Associate, and Full professor), particularly in terms of the number of papers published in journals indexed in Thomson Reuters Science Citation Index Expanded (SCle) and the Social Science Citation Index $(\mathrm{SSCl})$. The results of the new criteria have been immediate: the number of published papers significantly increased (Ivanovic; Ho, 2014). Along with it, the UB's rank on the ARWU list improved and moved into the top 301-400 (Zornic; Markovic; Jeremic, 2014).

Increasing academic activity and publication are not only spurred by university rankings. Universities, faculties, and their employees can be motivated to be proliferate publishers if their governments adopt performance funding budget allocation systems (Geuna; Martin, 2003). Additionally, universities have undergone a revolution where they have to incorporate entrepreneurial science in their curricula in addition to teaching and research (Etzkowitz, 1998). Prolific academic publishers are now encouraged to take part in the ideas development and opportunity search processes that can later be commercialized (Jain; George; Maltarich, 2009). The industry is turning its attention towards academia, recognizing the potential mutual benefits of cooperation. Gulbrandsen and Smeby (2005) found that industrial funding of academic research had a positive impact on the professors' research activity, publishing productivity, collaboration, and patent production.
Looking back to university rankings, several novel issues have emerged, which should be closely inspected. First, current ranking methodologies are solely focused on ranking universities, without examining the scientific achievement of faculties and institutes that make their integral parts. This aspect is particularly important when analyzing HEls in developing countries that do not have a large number of universities. Accordingly, the evaluation and ranking of the scientific performance of each faculty, school, or institute within a university would be more adequate and would lead to more transparency in the methods used to point out leading institutions. Secondly, the present rankings tend to put under the spotlight the research results of HEls oriented on "hard science" research, leaving the performance of institutions oriented towards arts, humanities, and social sciences in the shadow (Rauhvargers, 2013). Nevertheless, there are even differences within the results of science research. A study conducted by Bornmann, De-Moya-Anegón, and Mutz (2013) proved that certain subject-specific types of institutions are in an advantageous position when it comes to ranking in terms of outcome performance. Finally, the productivity of an individual $\mathrm{HEl}$ is often purely measured as the sum of papers published in a particular period. For example, one of the indicators of the ARWU ranking is Papers indexed in SCle and SSCI (ARWU, 2014), which is focused on the quantity of papers published (in reputable journals). This kind of measure does not take into account important bibliometric characteristics of papers (especially impact characteristics) published by a university and its institutions. This example precisely shows the importance of choosing advanced bibliometric indicators to be included in a ranking methodology. There are ranking methodologies available that completely rely on percentile-based bibliometric indicators. For example, the Leiden ranking measures the scientific impact and the scientific collaboration of the university using percentile-based indicators. This ranking utilizes indicators that are obtained by following strict and precise rules of data selection (Waltman et al., 2012; Hicks et al., 2015).

Current ranking methodologies are exclusively focused on ranking universities as a whole, not on examining scientific achievements of faculties and institutes that make their integral parts

Having in mind all the previously noticed issues, a conclusion can be made that there is a need for further improvement of ranking methodologies (Marope; Wells; Hazelkorn, 2013). This study aims to give new proposals for overcoming the above-mentioned slight methodological imperfections. The suggestions, if applied to higher educational systems, might provide valuable and straightforward information not only to end users (students, their parents and industry) but also to decision-makers. The authors' proposals, altogether, are aimed towards creating a framework for ranking institutions within a university. The "shiny" example, on which the framework is tested, the $U B$, comprises of 31 faculties 
and 11 institutes. Although Ivanovic and Ho (2014) analyzed the publishing activity of Serbia's universities, they perceived universities as a whole and did not take into account the performance of individual faculties and institutes within them. Our study, besides ranking institutions within a certain university, also aims at offering each institution the ability to see their contribution to the overall scientific performance of the university.

At the same time, a need for a more in-depth university ranking methodology emerges as governments worldwide are forced to cut down on higher education funding (Charles; Kitagawa; Uyarra, 2014; Heck; Lam; Thomas, 2014; Reale; Primeri, 2014). Such policy makes it even more difficult for institutions to get full government support, but also makes the country's universities and their institutions more competitive among themselves. In the case of the UB, each institution within it is an individual, legal, and governmentsupported entity. It is important to note that this is comparable to the status of departments within a university in other countries' higher educational systems. This study and its results might lead to a new framework for ranking educational institutions not only in Serbia and the $U B$, but in other developing countries, regardless the structure of their higher educational system.

The framework methodology is based on two approaches: bibliometrics and the I-distance approach

\section{Methods}

\subsection{Data set}

The subject of obtaining data for ranking institutions based on their scientific performance turns out not to be a straightforward task for several technical reasons. The first one, especially interesting for this study, is the problem of attributing publications to specific universities and later to institutions within it. Although research productivity of universities is accessible through Thomson Reuters Web of Knowledge platform (Thomson Reuters, 2014), their names are not entirely standardized. The same accounts for the names of institutes and faculties within the university. Another fact, which should also be taken into consideration, is that educational systems significantly differ worldwide. For that, the question of organizational structure and the relationship between both faculties and institutes within a university arises when assigning citations (Van-Raan, 2005). More precisely, authors' institutional affiliation-related inconsistency is visible on four levels: the department, the "mother" institution, the city, and the country (Melin; Persson, 1996). Despite the fact that bibliometric databases are becoming more and more sophisticated, the lack of consistency on the micro-level still exists. Several studies have been conducted (Gálvez; De-Moya-Anegón, 2006; Tang; Walsh, 2010) in order to systematize data in terms of affiliation with less effort and more speed.
These obstacles make it even more difficult for researchers to examine thoroughly the performance of a university and provide a detailed overview of its faculties and institutes. The absence of standardization in identifying author's affiliations and a considerable amount of data are just a few reasons why a comprehensive analysis of universities' institutions has been scarcely carried out on a large scale.

Considering all the above-mentioned obstacles encountered, a data set for the $U B$ and all of its 31 faculties and 11 institutes was created. Documents, whose quantity and impact characteristics were examined, were acquired from the SCle and the SSCl in the period 2008-2013. The publication data used in this study was obtained via Thomson Reuters Web of Knowledge from $1^{\text {st }}$ to $11^{\text {th }}$ November 2014.

The primary data set contained basic bibliometric data for 16,498 documents published by the faculties and institutes of the UB. Afterwards, the data set was refined following the standard in studies that evaluate research productivity from a bibliometric point of view. Accordingly, three types of documents were taken into account: Articles, Letters and Reviews (Bornmann et al., 2014). The data set with three document types has 7,718 documents for the four-year period (2008-2011).

\subsection{Percentile based approach}

Recent bibliometric research has labelled percentiles as a new method suitable for normalization of citation counts of publications in terms of document type, subject category, and publication year (Bornmann, 2013; Bornmann; Marx, 2014). Before percentiles, the common method of normalization was the mean normalized citation score (MNCS), which is based on arithmetic means of citations (Waltman et al., 2011). The main advantage of the new approach is that it overcomes the problem of citation distribution skewness (Bornmann, 2013). Waltman and Schreiber (2013, p. 372) defined a percentile-based bibliometric indicator as "an indicator that values publications based on their position within the citation distribution across their field". Likewise, Bornmann (2013, p. 587) emphasized the ability of percentiles to "provide information about the impact the publication in question has had compared to other publications (in the same area and publication year)". These definitions point out that percentiles can be used for meaningful analysis of bibliometric data (Bornmann; Leydesdorff; Mutz, 2013).

Since they were first introduced, the percentile-based indicators proliferated. Among many others, this study is based on four different percentile approaches: the percentile indicator used by InCites (PERC INCITES $)$ by Thomson Reuters, the percentile indicator based on Hazen's formula (PERC ${ }_{\text {HAZEN }}$ ), $P 100$, and $P 100^{\prime}$.

Prior to any bibliometric analysis based on percentiles, the reference set has to be determined. It is made of publications from the subject area, the same publication year, and documents of the same type as the publications being observed. In addition, a rank-frequency function has to be determined. In the case of PERC INCITES all publications in the 
reference set should be sorted in descending order. This indicator is calculated as follows: $\left((i / n)^{*} 100\right)$, where $i$ stands for the rank number of the publication in the reference set, and $n$ is the number of papers in the reference set. The mean value of the reference list not being 50 is a drawback of PERC INCITES which led to the application of Hazen's formula: ((i-0.5)/n*100) (Hazen, 1914). Besides Hazen's formula, several other percentile-based indicators have been developed, such as $P 100$ and $P 100$ '. In the case of all these indicators, the reference set is sorted in ascending order, contrary to the PERC INCITES . Thus, percentiles calculated on the InCites method are called inverted percentiles.

Namely, $P 100$ is a relatively new citation-rank indicator whose main advantage over other percentile-based indicators is that it scales the rank classes from 0 to 100 , where the highestranked paper in the reference set is at 100 and the lowest at 0 (Bornmann; Leydesdorff; Wang, 2013). This indicator can be calculated by the following formula: $\left(\left(i / i_{\max }\right) * 100\right)$. Some of the disadvantages of this indicator are that it cannot be obtained if all papers in the reference set have the same number of citations, and that the scale value of a paper can increase because another paper in a reference set receives additional citation (Bornmann; Mutz, 2014).

$P 100^{\prime}$ is an enhancement of the indicator $P 100$. Unlike $P 100$, the ranks for $P 100$ ' are not only based on the unique citation distribution (Bornmann; Mutz, 2014), but they also take into consideration the frequency of papers with the same citation counts. Papers with the same citation count are all assigned the same rank $j$, whereas the following paper with more citations has the rank $j+1$. When calculating $P 100$, each rank $j$ assigned to a paper is divided by the highest rank $j_{\max }$ or $(n-1)$ papers in the reference set and then it is multiplied by 100 , more precisely $\left(\left(j / j_{\max }\right) * 100\right)$ (Bornmann; Mutz, 2014). Same as P100, $P 100^{\prime}$ cannot be obtained if all papers in the reference set have the same number of citations.

\subsection{I-distance method}

The ranking obtained by a specific ranking methodology can have a severe effect on the assessment of institutional reputation (Bowman; Bastedo, 2011). Therefore, it can have serious implications on the number of applicants to a university or its faculties (Horstschräer, 2012). Besides influencing the number of interested prospective students, the results of rankings might have an impact on the funds allocated to a university and consequently to its faculties and institutes (Hazelkorn, 2007). In addition, several widely accepted ranking methodologies have been criticized for subjectively assigning weights to input indicators (Jeremic et al., 2011; Dobrota et al., 2015a). In an attempt to overcome this drawback, an impartial statistical methodology was implemented in our framework.

The need for an impartial ranking first appeared in the 1960s when countries had to be ranked by the level of their development based on several socio-economic indicators. One of the devised methodologies, which could answer such a task, was the I-distance method developed by Ivanovic (1977). His metric easily solves the problem of incorporating various indicators of different measurement units into a single synthetic indicator, which thereafter represents the rank (Jeremic et al., 2013). Besides being used to rank countries, in the last couple of years, the I-distance method was applied with success in the field of university ranking and assessing current ranking methodologies of universities (Jeremic et al., 2011; Jovanovic et al., 2012; Radojicic; Jeremic, 2012; Jeremic et al., 2013). Additionaly, since it is able to overcome the problem of subjectivity in a composite indicator, the I-distance method was used as the aggregation method in our study.

In order to apply the I-distance method, it is necessary to fix one entity as a reference in the observed data set. The fixed or reference entity is the entity with the minimal value for each indicator. If not applicable, it can be a fictive entity with the minimal value of each indicator. The ranking of entities in the data set is founded on the calculated distance from the reference entity (Jovanovic et al., 2012). The construction of the I-distance is an iterative process, which consists of several steps. The first step calculates the amount of discriminate effect of the first variable (the most significant variable that provides the most information on the ranking phenomenon); the second step calculates the value of the discriminate effect of the second variable, not included in the first. This procedure is repeated for all the variables in the observed data set.

Let $X^{T}=\left(X_{1}, X_{2}, \ldots X_{k}\right)$ be a set of variables chosen to characterize the entities. I-distance between two entities $e_{r}=\left(x_{1 r}\right.$ $\left.x_{2,}, \ldots x_{k r}\right)$ and $e_{s}=\left(x_{1 s^{\prime}}, x_{2 s^{\prime}} \ldots X_{k s}\right)$ is defined as

$$
D(r, s)=\sum_{i=1}^{k} \frac{\left|d_{i}(r, s)\right|}{\sigma_{i}} \prod_{j=1}^{i-1}\left(1-r_{j i .12 \ldots j-1}\right)
$$

where $d_{i}(r, s)$ is the discriminate effect, the distance between the values of the variable $X_{i}$ for $e_{r}$ and $e_{s}$

$$
d_{i}(r, s)=x_{i r}-x_{i s} \quad i \in\{1, \ldots k\}
$$

$\sigma_{i}$ is the standard deviation of $X_{i}$ and $r_{j i, 12, \ldots j-1}$ is the partial coefficient of the correlation between $X_{i}$ and $X_{i},(j<i)$ (Radojicic; Jeremic, 2012).

In addition, frequently used square I-distance provides additional benefits (Jeremic et al., 2013). It is given as:

$$
D^{2}(r, s)=\sum_{i=1}^{k} \frac{d_{i}^{2}(r, s)}{\sigma_{i}^{2}} \prod_{j=1}^{i-1}\left(1-r_{j i .12 \ldots j-1}^{2}\right)
$$

\section{Results}

\subsection{Results of the basic bibliometric analysis}

The number of published documents per faculty and institute was determined for each observed year. The obtained results of institutions with at least 500 papers published in the six-year period are shown in table 1. 
Table 1. Number of papers the UB's faculties and institutes published on SCle and SSCI lists for each observed year and in total for the period 2008-2013

\begin{tabular}{|c|l|r|r|r|r|r|r|r|}
\hline Rank Faculty or Institute & $\mathbf{2 0 0 8}$ & $\mathbf{2 0 0 9}$ & $\mathbf{2 0 1 0}$ & $\mathbf{2 0 1 1}$ & $\mathbf{2 0 1 2}$ & $\mathbf{2 0 1 3}$ & Total \\
\hline 1 & Faculty of Medicine & 241 & 327 & 374 & 497 & 672 & 755 & 2,866 \\
\hline 2 & Vinca Institute of Nuclear Science & 276 & 308 & 321 & 438 & 660 & 589 & 2,592 \\
\hline 3 & Institute of Physics & 117 & 189 & 133 & 206 & 334 & 249 & 1,228 \\
\hline 4 & Faculty of Technology and Metallurgy & 117 & 156 & 159 & 197 & 238 & 266 & 1,133 \\
\hline 5 & Institute for Chemistry, Technology, and Metallurgy & 107 & 144 & 145 & 178 & 204 & 212 & 990 \\
\hline 6 & Institute for Biological Research "Sinisa Stankovic" & 143 & 124 & 141 & 145 & 207 & 216 & 976 \\
\hline 7 & Faculty of Biology & 136 & 107 & 115 & 133 & 171 & 193 & 855 \\
\hline 8 & Faculty of Chemistry & 92 & 103 & 109 & 134 & 168 & 187 & 793 \\
\hline 9 & Faculty of Physics & 60 & 56 & 74 & 139 & 166 & 167 & 662 \\
\hline 10 & Faculty of Mechanical Engineering & 41 & 70 & 82 & 135 & 174 & 138 & 640 \\
\hline 11 & Faculty of Electrical Engineering & 74 & 96 & 84 & 114 & 132 & 119 & 619 \\
\hline 12 & Faculty of Agriculture & 45 & 49 & 111 & 114 & 142 & 141 & 602 \\
\hline 13 & Faculty of Pharmacy & 62 & 78 & 63 & 96 & 139 & 155 & 593 \\
\hline 14 & Faculty of Physical Chemistry & 75 & 85 & 77 & 114 & 102 & 118 & 571 \\
\hline
\end{tabular}

Note: A particular paper can be the result of collaboration between faculties and institutes within the UB, and for that, the paper is affiliated to all institutions that participated in it in the overall year count (thus we applied full counting)

As we can see, the Faculty of Medicine and the Vinca Institute of Nuclear Science lead the way. Since 2008, both of these institutions have more than doubled their output. They should be, without any doubt, credited as the stepping-stone of the UB's rise in ARWU ranking. The rest of the top 14 institutions are mostly oriented towards science subjects, such as physics, chemistry, and biology. The first

Table 2. Number of papers and their quality characteristics for UB faculties (with at least 100 papers published in the period 2008-2011)

\begin{tabular}{|l|l|c|c|c|}
\hline \multicolumn{1}{|c|}{ Faculty } & Abbreviation & Papers & $\begin{array}{c}\text { Leading } \\
\%\end{array}$ & IC \% \\
\hline Faculty of Medicine & MED & 1,439 & 57.54 & 26.34 \\
\hline Faculty of Technology and Metallurgy & T\&M & 629 & 55.17 & 27.50 \\
\hline Faculty of Biology & BIO & 491 & 46.44 & 35.03 \\
\hline Faculty of Chemistry & CHEM & 438 & 39.95 & 35.84 \\
\hline Faculty of Electrical Engineering & EE & 368 & 50.82 & 43.75 \\
\hline Faculty of Physical Chemistry & PCHEM & 351 & 46.15 & 31.05 \\
\hline Faculty of Physics & PHYS & 329 & 39.21 & 57.14 \\
\hline Faculty of Mechanical Engineering & ME & 328 & 63.41 & 23.48 \\
\hline Faculty of Agriculture & AGR & 319 & 40.13 & 33.54 \\
\hline Faculty of Pharmacy & PHARM & 299 & 56.19 & 28.43 \\
\hline Faculty of Mathematics & MATH & 219 & 61.64 & 32.42 \\
\hline Faculty of Mining and Geology & MG & 200 & 49.50 & 41.50 \\
\hline Faculty of Veterinary Medicine & VET & 170 & 41.76 & 26.47 \\
\hline Technical Faculty in Bor & TECHB & 164 & 68.29 & 16.46 \\
\hline Faculty of Dental Medicine & DENT & 163 & 50.92 & 35.58 \\
\hline Faculty of Organizational Sciences & FOS & 119 & 52.10 & 30.25 \\
\hline Faculty of Philosophy & PHIL & 104 & 65.38 & 22.12 \\
\hline
\end{tabular}

Note: Papers - Total number of papers published by a faculty in the period 2008-2011; Leading $\%$ - Percentage of papers in which the leading author is from a particular faculty; IC \% Percentage of papers with international collaboration institution on the list that is primarily focusing on social sciences is the Faculty of Philosophy, which takes the $26^{\text {st }}$ position with 161 published papers. On the other hand, more than ten institutions (some of them sciencebased) published less than 100 papers each in the observed period. This simple and rather superficial analysis clearly implies that there is a substantial disparity among the $U B$ institutions. Overall, institutes are ranked higher than faculties when it comes to the total number of published papers. One can argue that this result is expected since the institutes are not engaged in the teaching process while their colleagues at faculties are. Consequently, this fact must be taken into consideration when ranking the institutions within a certain university. For that, institutes will be listed out of our further analysis, as we focus more on individual faculties' contribution and performance.

In addition to analyzing just the number of published papers, we wanted to shed light on the assignment of the leading author of a paper to a faculty and the international collaborative research patterns. Simple bibliometric indicators related to citations and impact factors of journals in which the papers were published (such as average impact factor and average citation) could not be used, as publication and citation patterns in the fields of science differ and are thus incomparable (Leydesdorff; Bornmann, 2011). We calculated the following indicators for each faculty in the four-year period: Number of published papers ( $\mathrm{Pa}$ pers), Percentage of papers in which the leading author is from a particular faculty (Leading \%), and the Percentage of papers with international collaboration (IC \%). The papers taken into account were published in the period 2008-2011. The results are shown in table 2.

As previously mentioned, the Faculty of Medicine leads the way in the number of published papers, followed by the Faculty of Technology and Metallurgy. Values of the indicator Leading \% marked the Technical Faculty in Bor as the faculty that was 
the leading author of most of its publications. The Faculty of Mechanical Engineering and the Faculty of Mathematics do not lag far behind being the leading author in $63.41 \%$ and $61.64 \%$ of published scientific research respectively. Faculties of Physics and Chemistry have clearly lower values. A closer inspection of their results implies that the Faculty of Physics is oriented to international collaboration $(57.14 \%)$, while it can be denoted that the Faculty of Chemistry is more prone to collaborating domestically, as its international collaboration is $35.84 \%$. Besides the Faculty of Physics, the leaders in international collaboration among $U B$ faculties, faculties of Electrical Engineering, and Mining and Geology, also have notable percentages of papers published in which at least one author was from an international institution. International collaboration of all these faculties might lead to the affirmation of the $U B$ and can be an example for other faculties to open themselves more to the international scientific community.

The fact that the obtained results of the three simple bibliometric indicators significantly differ among the observed faculties, and even among the ones oriented on the same group of sciences, is just another proof that bibliometric indicators for institutions cannot be compared among scientific fields (Leydesdorff, 2007). Also, these three indicators cannot provide the stakeholder sufficient information on the rank of the scrutinized institutions. Namely, one cannot claim that a faculty or an institute is better than the other(s) by just taking into account the number of published papers or their collaboration behavior. This analysis can intrigue the stakeholder to raise the question whether there are differences in the impact and importance between the total number of papers published by an institution and the ones it published as the leading author.

To overcome the above-described limitations of simple bibliometric indicators a percentile-based approach will be implemented in our framework. Additionally, in order to obtain an in-depth overview of the scientific performance of the UB institutions, the percentile-based approach was performed from two viewpoints: first, when all the papers published by a faculty were analyzed and second, when just the papers in which the leading author is from a particular faculty were taken into account.

\subsection{I-distance method ranking based on percentile indicators}

Several studies (Bornmann; Marx, 2014; Bornmann; Leydesdorff; Mutz, 2013) evaluated universities and even individual researchers using percentiles and percentile rank classes (PRs). As Bornmann, Leydesdorff, and Mutz (2013) show, there are several methods to calculate percentiles. Therefore, multiple percentile-based indicators can be used in assessing

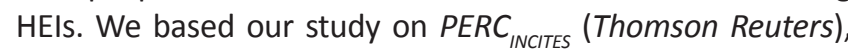

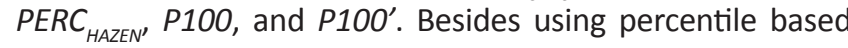
indicators, we incorporated the standard bibliometric indicator MNCS into our analysis. Rehn, Kronman, and Wadskog (2007, p. 13) defined it as an "indicator that represents a relative number of citations to publications from a specific unit, compared to the world average of citations to publications of the same document type, age and subject area". Although the percentile-based approach is accepted in bibliometrics as a valuable addition to previously devised methods based on normalization of citation counts, uncertainty regarding the choice of a proper percentile approach still remains (Bornmann; Leydesdorff; Wang, 2013).

Together with MNCS, previously presented percentile-based indicators can provide an in-depth bibliometric analysis of a particular scientific institution. In order to overcome the question of choice of just one percentile-based approach, we decided to incorporate all of the indicators mentioned above into a single rank using the I-distance method. Besides ranking all UB faculties with more than 100 published papers in total, faculties were also ranked by taking into account only the papers in which the observed faculty was the leading author. The results obtained are presented in table 3 .

\section{Such a comprehensive novel approach} for evaluating educational institutions promises to be useful to students, academia and policy makers in decisionmaking

Total I-distance results show that the Faculty of Physics and the Faculty of Medicine lead the way, whereas the Faculty of Veterinary Medicine and the Faculty of Mining and Geology lag behind. The Faculty of Physics found its place on top of the ranks thanks to the exceptionally high value of the indicator $P 100$. It is a clear demonstration that the papers they published are of higher impact than the corresponding papers in the reference set. Despite the fact that the Faculty of Medicine has more than four times more published papers than the Faculty of Physics in the period 2008-2011, its lower values of $P 100$ and MNCS positioned it on the second place. An interesting result is seen with the Faculty of Organizational Sciences making it to the $6^{\text {th }}$ place. Although it has the least papers published in the analyzed group, relatively high values of $P 100$ and MNCS launched it up the ranks. Also, a result that was not expected is the Faculty of Electrical Engineering not making it into top 8. However its papers had a higher value of the indicator PERC INCITES $_{\text {than }}$ the papers published by the Faculty of Physics, their significantly lower number of cites led to a lower value of $P 100$ and eventually to rank below top 8 .

Results of the leading I-distance analysis display thoughtprovoking ranks. Now the Faculty of Mechanical Engineering leads the rank, whereas the Faculty of Medicine remained second. At the same time, there are no significant changes in the bottom of the rank. Several faculties significantly improved their ranks, wherein the Technical Faculty in Bor stands out. Namely, it has improved its rank by nine places, from $14^{\text {th }}$ to $5^{\text {th }}$ place. Such a result could be expected as this faculty has the highest percentage of papers with the leading author being their researcher. Moreover, its $P 100$ values do not lag behind the leading ones. One should inspect more closely the Faculty of Physics and the Faculty of Dental Medicine, which dropped ranks by nine and eight places respectively. Both faculties saw values 
Table 3. Number of published papers from 2008 to 2011 per faculty, their MNCS and percentile-based indicators, followed by their rank obtained by the I-distance method for two cases analyzed: the total number of papers published by an institution and the papers in which a certain institution was the leading author.

\begin{tabular}{|c|c|c|c|c|c|c|c|c|c|c|c|c|c|c|}
\hline \multirow{2}{*}{ Faculty } & \multicolumn{7}{|c|}{ Total } & \multicolumn{7}{|c|}{ Leading } \\
\hline & Papers & MNCS & PERC $_{\text {INCITES }}$ & PERC $_{\text {HAZEN }}$ & P100 & $P 100^{\prime}$ & $\begin{array}{c}\text { I-distance } \\
\text { rank }\end{array}$ & Papers & MNCS & PERC $_{\text {INCTES }}$ & PERC $_{\text {HAZEN }}$ & P100 & P100' & $\begin{array}{c}\text { I-distance } \\
\text { rank }\end{array}$ \\
\hline Faculty of Medicine & 1,439 & 0.59 & 67.68 & 37.41 & 4.67 & 31.59 & 2 & 828 & 0.39 & 72.73 & 32.92 & 3.10 & 26.45 & 2 \\
\hline $\begin{array}{l}\text { Faculty of Technolo- } \\
\text { gy and Metallurgy }\end{array}$ & 629 & 0.80 & 56.11 & 45.79 & 6.28 & 41.49 & 3 & 347 & 0.77 & 56.60 & 45.28 & 6.30 & 41.13 & 3 \\
\hline Faculty of Biology & 491 & 0.51 & 68.21 & 35.44 & 4.38 & 30.93 & 12 & 228 & 0.45 & 72.48 & 31.46 & 3.80 & 26.76 & 12 \\
\hline Faculty of Chemistry & 438 & 0.60 & 61.03 & 41.42 & 4.65 & 37.59 & 9 & 175 & 0.57 & 60.41 & 41.88 & 4.42 & 38.06 & 7 \\
\hline $\begin{array}{l}\text { Faculty of Electrical } \\
\text { Engineering }\end{array}$ & 368 & 0.78 & 61.02 & 43.84 & 4.47 & 37.16 & 10 & 187 & 0.79 & 60.19 & 44.62 & 4.54 & 37.93 & 6 \\
\hline $\begin{array}{l}\text { Faculty of Physical } \\
\text { Chemistry }\end{array}$ & 351 & 0.66 & 60.40 & 41.33 & 4.80 & 37.46 & 8 & 162 & 0.60 & 61.45 & 39.85 & 3.99 & 35.90 & 11 \\
\hline Faculty of Physics & 329 & 1.51 & 49.22 & 52.86 & 8.44 & 48.97 & 1 & 129 & 0.61 & 61.92 & 41.06 & 4.10 & 36.36 & 10 \\
\hline $\begin{array}{l}\text { Faculty of Mechani- } \\
\text { cal Engineering }\end{array}$ & 328 & 1.17 & 60.19 & 45.01 & 6.09 & 38.16 & 4 & 208 & 1.27 & 59.84 & 45.21 & 6.61 & 38.28 & 1 \\
\hline $\begin{array}{l}\text { Faculty of Agricul- } \\
\text { ture }\end{array}$ & 319 & 0.56 & 65.55 & 38.68 & 4.75 & 32.98 & 11 & 128 & 0.42 & 73.13 & 32.14 & 3.46 & 25.75 & 14 \\
\hline Faculty of Pharmacy & 299 & 0.54 & 63.93 & 39.06 & 4.37 & 34.78 & 13 & 168 & 0.51 & 62.99 & 39.37 & 4.27 & 35.37 & 9 \\
\hline $\begin{array}{l}\text { Faculty of Mathe- } \\
\text { matics }\end{array}$ & 219 & 1.11 & 62.16 & 45.30 & 4.75 & 36.94 & 7 & 135 & 0.92 & 65.24 & 43.53 & 3.94 & 33.99 & 8 \\
\hline $\begin{array}{l}\text { Faculty of Mining } \\
\text { and Geology }\end{array}$ & 200 & 0.43 & 70.67 & 34.63 & 4.01 & 27.17 & 15 & 99 & 0.31 & 77.21 & 30.02 & 2.44 & 21.04 & 16 \\
\hline $\begin{array}{l}\text { Faculty of Veterinary } \\
\text { Medicine }\end{array}$ & 170 & 0.39 & 77.02 & 31.15 & 2.85 & 23.06 & 16 & 71 & 0.37 & 78.32 & 30.99 & 2.68 & 21.85 & 15 \\
\hline $\begin{array}{l}\text { Technical Faculty } \\
\text { in Bor }\end{array}$ & 164 & 0.55 & 66.10 & 37.97 & 4.12 & 31.72 & 14 & 112 & 0.67 & 60.46 & 42.30 & 5.19 & 36.68 & 5 \\
\hline $\begin{array}{l}\text { Faculty of Dental } \\
\text { Medicine }\end{array}$ & 163 & 0.60 & 65.03 & 40.05 & 5.83 & 33.87 & 5 & 83 & 0.39 & 72.75 & 33.94 & 3.85 & 26.71 & 13 \\
\hline $\begin{array}{l}\text { Faculty of Organiza- } \\
\text { tional Sciences }\end{array}$ & 119 & 1.02 & 61.46 & 45.83 & 5.17 & 38.17 & 6 & 62 & 0.97 & 61.42 & 46.40 & 5.55 & 37.62 & 4 \\
\hline
\end{tabular}

Note: MNCS - Mean normalized citations score; PERC INCITES $_{-}$Percentile indicator used by InCites (Thomson Reuters); $P$ ERC ${ }_{\text {HAZEN }}$ - Percentile indicator based on Hazen's formula; P100 - Citation-rank indicator developed by Bornmann et al. (2013c); P100' - Citation-rank indicator developed by Bornmann \& Mutz (2014).

of their $P 100$ and MNCS plummet when papers authored by their affiliates were scrutinized. When the Faculty of Physics was not the leading author, it usually collaborated with international institutions and the Vinca Institute of Nuclear Science. The papers with the leading authors from international institutions written in collaboration with the researchers from the Faculty of Physics and the Vinca Institute of Nuclear Science are of particular interest for this analysis. The average impact factor of these 96 papers is 5.103 , while its average citation rate is 23.146 . In the case of the Faculty of Dental Medicine, among the 80 papers on which this faculty was not the leading author, half were written in collaboration with international institutions, while the other half was published together with $U B$ institutions. The average citations of these coauthored papers is 6.112 , which is by a fifth more than the remaining ones whose average citations is 4.840 . A decline of the average citations had an adverse impact on the value of the indicator P100 and consequently on the leading I-distance rank of both Faculty of Physics and Faculty of Dental Medicine.

As I-distance method ranks entities utilizing all indicator values, the question of each indicator's contribution to the final rank arises. To obtain such information the Pearson's correlation coefficient of each variable with the acquired I-distance value was determined. Table 4 shows that in both analyzed cases the indicator $P 100$ is the most significant for the ranking process, which means it provides the largest amount of information. Similarly, MNCS did not change its significance rank after the removal of papers in

Table 4. The correlation between indicators and I-distance value in the case when total number of papers was analyzed and in the case when only the papers where a certain institution was the leading author were analyzed.

\begin{tabular}{|c|c|c|c|}
\hline \multicolumn{2}{|c|}{ Total } & \multicolumn{2}{|c|}{ Leading } \\
\hline Indicator & Correlation & Indicator & Correlation \\
\hline P100 & $0.854^{* *}$ & P100 & $0.674^{* *}$ \\
\hline PERC $C_{\text {INCITES }}$ & $0.751^{* *}$ & Papers & $0.633^{* *}$ \\
\hline MNCS & $0.711^{* *}$ & MNCS & $0.611^{* *}$ \\
\hline$P 100^{\prime}$ & $0.705^{* *}$ & $P E R C_{\text {HAZEN }}$ & $0.515^{* *}$ \\
\hline$P E R C_{\text {HAZEN }}$ & $0.676^{* *}$ & $P E R C_{\text {INCITES }}$ & $0.495^{* *}$ \\
\hline Papers & $0.436^{* *}$ & $P 100^{\prime}$ & $0.492^{* *}$ \\
\hline
\end{tabular}

Note: ${ }^{* *} \mathrm{p}<0.01$ 
which a certain institution was not the leading author. An interesting shift in the level of correlation can be seen in the

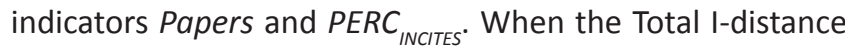
was calculated, Papers came out as the least important for the ranking process with $r=0.436$, but afterwards, when co-authored papers were removed from the analysis, it's correlation coefficient rose to $r=0.633$. On the other hand, $P E R C_{\text {INCITES }}$ dropped its significance from $r=0.751$ (Total papers) to $r=0.495$ (Leading papers).

Apart from analyzing the shifts in faculty's I-distance rank in regard to either all published papers or just the ones where the faculty was the leading author, attention should be given to the (in)consistency of percentile-based indicators in both cases. For example, the Faculty of Technology and Metallurgy, the Faculty of Electrical Engineering, and the Faculty of Mechanical Engineering, all display a high level of consistency in both cases. On the other hand, the values of percentile-based indicators of the Faculty of Physics and the Faculty of Dental Medicine decreased after the papers where these institutions were not the leading authors were removed. This result shows that the research, where the leading author was from these institutions, is not on the same level as the one on which the researchers from these institutions took part as co-authors. This might also mean that these institutions have the expertise, but no sufficient funds to conduct sophisticated research by themselves.

Besides examining the obtained ranks and the percentilebased indicators (in)consistency, further results can be acquired from a thorough percentile analysis (Bornmann; Leydesdorff; Mutz, 2013). For instance, violin plots can be successfully used for a visual inspection of percentile-based indicators. A violin plot shows the median of data and a box indicating the interquartile range. What makes this plot different from others is its ability to provide a better indication of the shape of the distribution and to point out the existence of clusters (Hintze; Nelson, 1998).

Percentiles can be classified into percentile rank classes (PRs) (Leydesdorff et al., 2011). These classes may explain performance results of institutions with more accuracy and precision. In addition, PRs are easy to interpret: they show the percent of papers an institution has published, and a certain rank class they belong to. The differences among various PRs can be used as a valuable mean of comparison of several institutions' scientific performance. Bornmann, Leydesdorff, and Mutz (2013) thoroughly elaborated four different class schemes that are common when analyzing percentiles. The class scheme used in this study is $\operatorname{PR}(6)$, which is a scheme with six rank classes (Bornmann; Mutz, 2011). The US National Science Foundation is using this approach as an evaluation scheme (National Science Board, 2012). The focus of this scheme is on publications that are cited more frequently than the median percentile (Bornmann; Leydesdorff; Mutz, 2013). The six percentile rank classes are defined as follows:

(1) $<50 \%$ (papers with a percentile smaller than the $50^{\text {th }}$ percentile),

(2) $50 \%$ (papers within the $\left[50^{\text {th }} ; 75^{\text {th }}\right.$ [percentile interval),

(3) $25 \%$ (papers within the $\left[75^{\text {th }} ; 90^{\text {th }}\right.$ [percentile interval),
(4) $10 \%$ (papers within the $\left[90^{\text {th }} ; 95^{\text {th }}\right.$ [percentile interval),

(5) $5 \%$ (papers within the $\left[95^{\text {th }} ; 99^{\text {th }}\right.$ [percentile interval),

(6) $1 \%$ (papers with a percentile equal to or larger than the $99^{\text {th }}$ percentile).

All of the $U B$ faculties with more than 100 published papers can be denoted as institutions predominantly oriented to "hard" sciences. Driven by the research conducted by Bornmann, De-Moya-Anegón, and Mutz (2013), the authors wanted to inspect more closely the patterns and differences within the values of percentile-based indicators of the observed science-based faculties. Accordingly, the faculties were categorized into three groups following the official UB organizational scheme (University of Belgrade, 2014): Technology and Engineering Sciences, Sciences and Mathematics, and Medical Sciences. The Faculty of Philosophy was ruled out from this analysis because it is the only institution from the group Social Sciences and $\mathrm{Hu}$ manities.

Figure 1 provides violin plots and percentile rank classes for the three groups of top ranked faculties based on the indicator PERC INCITES (table 3) for the total number of papers which these institutions have published in the observed time period. In the case of faculties in the group Technology and Engineering Sciences (figure 1a), four institutions exhibit remarkable results as shown by the violin plots. Two out of four faculties in this group have more than the expected $1 \%$ value of the class $1 \%$ papers. With a value of $4.27 \%$, the Faculty of Mechanical Engineering is the UB faculty with the highest value of the class $1 \%$ papers, whereas the $\mathrm{Fa}$ culty of Electrical Engineering has the second best value with $1.09 \%$. When it comes to the class $5 \%$ papers some institutions have values higher than expected (the Faculty of Organizational Sciences and the Faculty of Technology and Metallurgy) or close to expected (the Faculty of Mechanical Engineering and the Faculty of Electrical Engineering). None of the observed faculties has values close to expected for classes $10 \%, 25 \%$, and $50 \%$. Among the three faculties not presented with a violin plot, Technical Faculty in Bor stands out with $1.83 \%$ in class $1 \%$. This result is worth mentioning, having in mind the fact that this faculty has the highest value of the indicator Leading \%.

Among five Sciences and Mathematics faculties, four displayed interesting results (figure 1b). The Faculty of Mathematics stands out as the institution with the highest percent of papers in class $1 \%$ with a value of $3.20 \%$, whereas the Faculty of Physics comes second best with a value of $2.13 \%$. Furthermore, the Faculty of Physics published nearly twice as many papers in the classes $5 \%$ and $10 \%$ than the expected value, making it one of the best faculties in terms of citation impact. The Faculty of Physical Chemistry and the Faculty of Chemistry, for instance, do not have high values for class $1 \%$ but have values that roughly agree with the expected value for class $10 \%$.

Among the faculties in the group of Medical Sciences (figure 1c), is the Faculty of Dental Medicine has the highest percentage of papers in class $1 \%$. Neither the Faculty of Pharmacy nor the Faculty of Veterinary Medicine have papers in this class. Although the Faculty of Medicine publis- 
Figure 1. Distributions of inverted percentiles visualized by violin plots showing the median and the interquartile range (left) and differences among faculties measured by $\mathrm{PR}(6)$ (right) based on the total number of papers published by a faculty.

a) Technology and Engineering Sciences

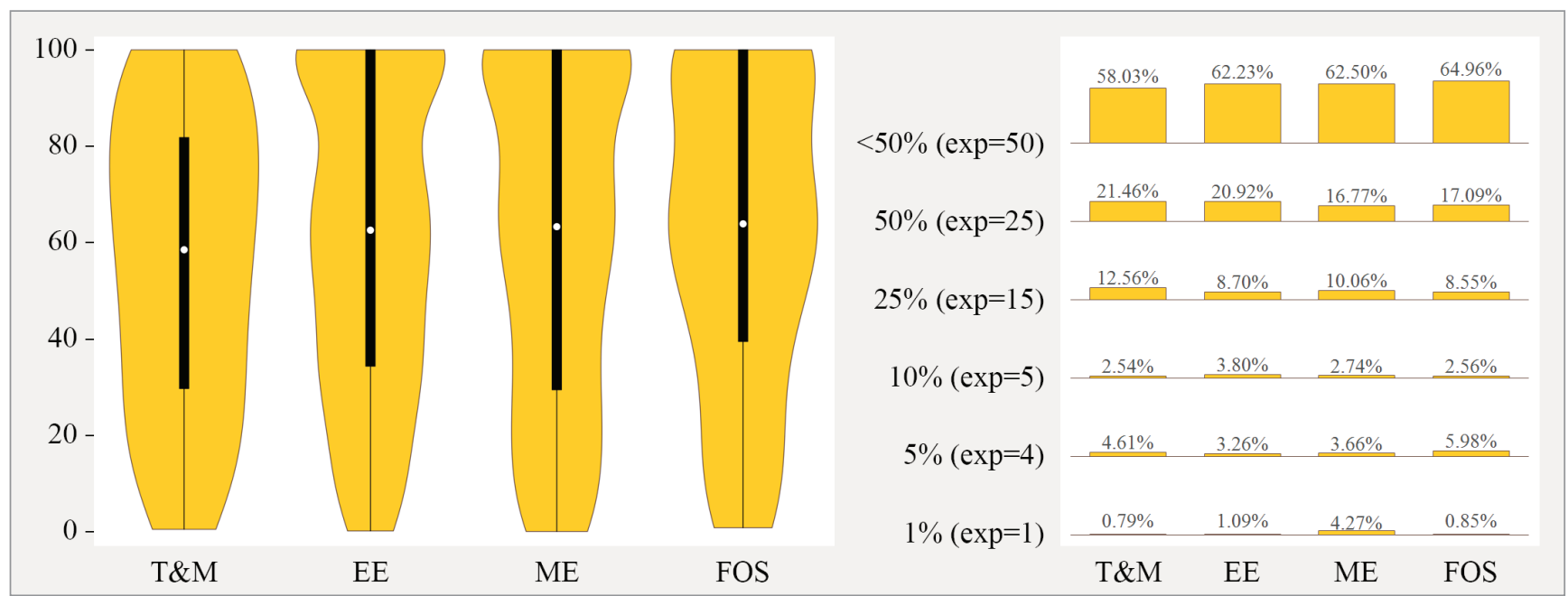

b) Sciences and Mathematics

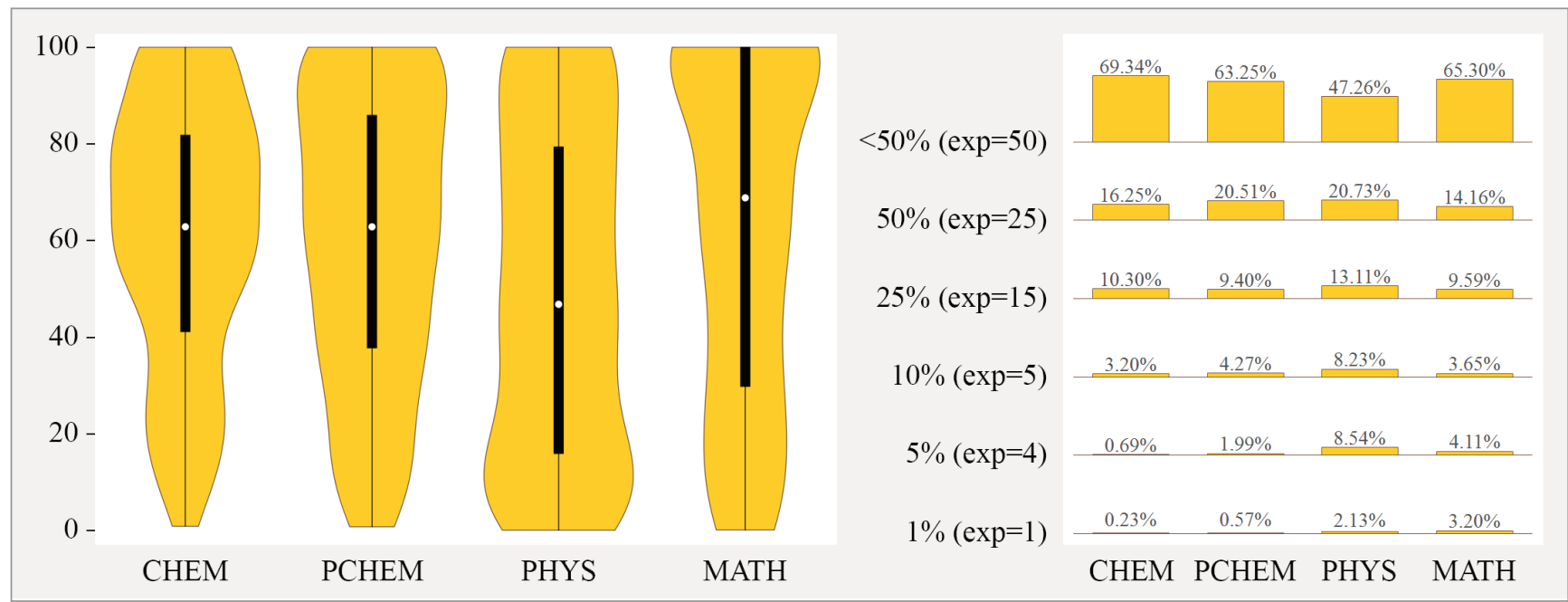

c) Medical Sciences

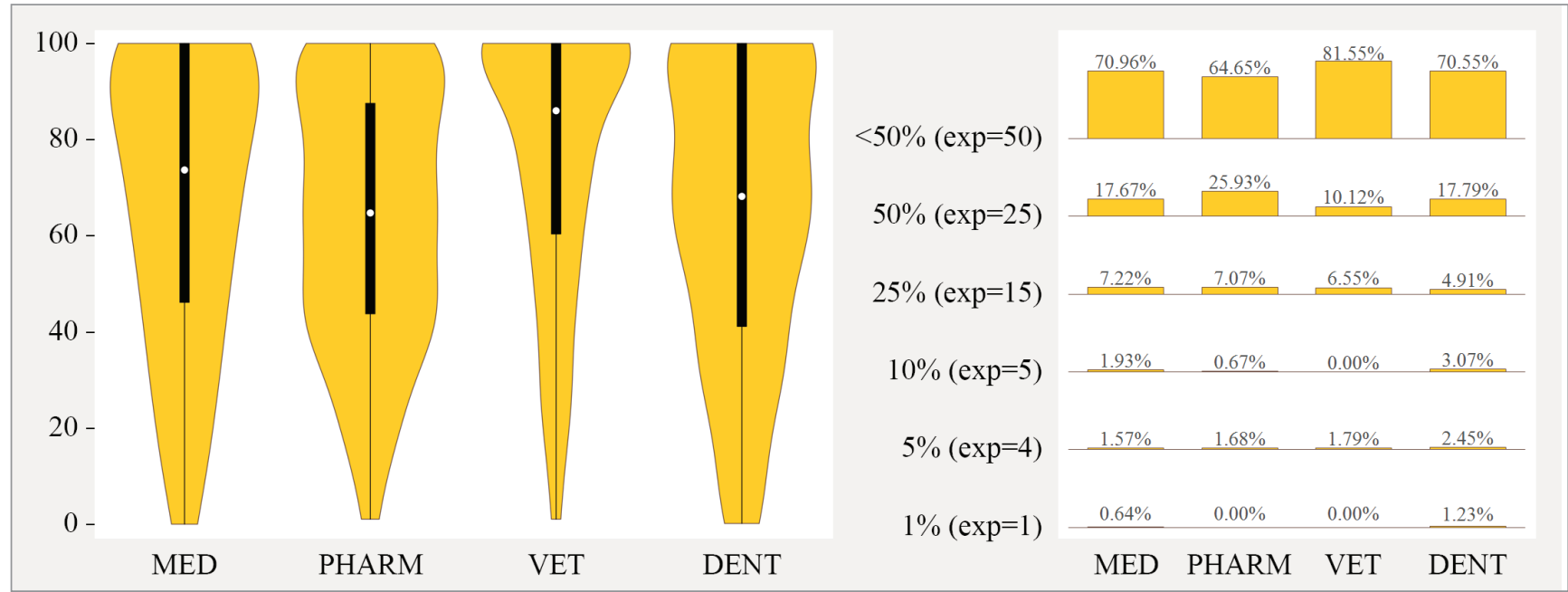

hed the most papers in the observed period, its PRs show that $70.96 \%$ of them can be classified in the $<50 \%$ class. All faculties in this group have published less class $5 \%, 10 \%$, and $25 \%$ papers than the expected values. In class $50 \%$, the Faculty of Pharmacy stands out with a value of $25.93 \%$, which is just over the expected value of $25 \%$. 


\section{Concluding remarks}

Over the last decade, world-class HEls ranking methodologies have proliferated, whereby many of them have different aims and scopes. Some are concerned with evaluating the role of leading individuals in achieving universities' high position on the ranking list (Abramo; Cicero; D'Angelo, 2013), while others are concerned with ranking institutions solely on scientific performance in one subject area (Acuña; Espinosa; Cancino, 2013). However, current ranking methodologies are exclusively focusing on ranking universities as a whole, and not on examining the performance of faculties and institutes that make their integral parts.

Attempts have been made to rank departments within a university, but with several limitations. For example, the study by Zhou and Leydesdorff (2011) does not specify which types of documents should be included in the study, while the study by Altanopoulou, Dontsidou, and Tselios (2012) ranked departments of different national universities. As a possible remedy, which might overcome the perceived obstacles, a novel framework for ranking faculties and institutes was created and examined on faculties in this study. The framework methodology is based on two approaches: bibliometrics and the I-distance approach. Many bibliometric indicators have been used to evaluate the scientific performance on the macro and micro level (Moed et al., 1985; Van-Raan, 2003; Chinchilla-Rodríguez et al., 2015a; 2015b), while the percentile-based indicators are emerging as a valuable tool for such analysis. The I-distance employed in this study stands out as an unbiased method of ranking institutions (Jeremic et al., 2013).

The presented framework consists of two steps: firstly, four percentile-based indicators and MNCS are calculated; and secondly, the I-distance method is applied to the (I) number of papers and (II) previously obtained indicators in order to determine the ranks of the institutions. The framework was solely tested on faculties because of the differing levels of research output between faculties and research institutes. The observed output difference is due to the distinctive nature of the two professions. Research institute affiliates completely focus on research while faculty affiliates, besides research, devote a lot of time to non-research activities. Such activities are related to teaching (Price; Cotten, 2006), grading student papers and mentoring BSc, MSc and PhD thesis, which all lead to the development of the next generation of scientific talent (Hurtado et al., 2011). Balance in research and teaching should be found (Brew; Boud, 1995), although such balance is fragile or often impossible to achieve (Barnett, 1992). The conclusion can be drawn that although institutes and faculties are part of the same university, their scientific output cannot be compared as researchers are not faced with the same activities (King, 1987). Accordingly, in this study only faculties were ranked.

Basic bibliometric "screening" of the UB denoted the Faculty of Medicine as the most productive one, with 1,439 papers published in the four-year period, the Technical Faculty in Bor as the faculty with the highest percentage of papers published as the leading author, and the Faculty of Physics as the institution which has the most developed interna- tional collaboration. As these simple bibliometric indicators cannot provide a stakeholder rank of observed institutions, percentile-based ones were used. Furthermore, the data set was perceived from two angles: the total papers published by a faculty, and the papers in which a faculty was the leading author.

The presented framework considers the application of the Idistance method on six indicators: four percentile-based indicators, the number of published papers in the observed period, and the MNCS. Obvious differences in the faculties' ranks were noted from the two observed angles. Institutions that experienced a sharp decline in ranks co-authored on a notable number of papers of high impact and importance. These faculties were replaced by the less internationally oriented ones or by the ones whose paper quality was consistent in both cases. The Spearman's correlation coefficient between the two obtained ranks is $r_{s}=0.565(p<0.05)$, meaning the correlation is large. Besides having more consistent results, the faculties in the group of Technology and Engineering Sciences also have more than the expected $1 \%$ value of class $1 \%$ papers than the other two groups (figure 1).

The main benefit of the proposed framework is its capability to rank institutions based on their scientific performance

The main benefit of the proposed framework is its capability to rank institutions based on their scientific performance and to point out the leaders and those who cannot easily follow their results. Another advantage is its wide appliance: it can be employed to every university and all its institutions. The aggregating method does not assign weights to indicators, so there is no possibility of different weights being assigned to the same indicators when analyzing any university other than the $U B$.

Limitations of the presented framework appear on two levels: on the input level and on the interpretation of the output. Namely, the process of accurate data acquisition is a daunting task. Although there are databases available, institutional names are not completely unified due to lack of standardization. This applies to all different levels of research institutions. Moed (2002) found out that up to $30 \%$ of citations might be lost due to wrong attribution of publications to research institutions. Such errors might be made due to wrong database entries, a high number of variants in naming a specific institution, identical indications of different institutions, wrong indications of the affiliation by the author due to complexity of the organizational structure (Abramo et al., 2008) or lack of the authors' explicit statement of the affiliation. Taking into account the aboveacknowledged possible errors, one can conclude that the collected input data might not completely cover the actual number of publications by a certain university and its institutions. On the other hand, bibliometric indicators and therefore ranking systems based on them have started to play a predominant role in science policy-making and budgetary 
decisions (Weingart, 2005b). As the results of bibliometric analysis are potentially politically critical and associated with strong interests (Bornmann; Marx, 2014), additional attention should be given to their interpretation. Policy makers and other stakeholders who try to interpret such ranking results without prior knowledge of bibliometrics or assistance from experts are almost certainly going to obtain misleading and meaningless conclusions (Weingart, 2005b). A code of professional ethics is therefore needed to regulate their (mis)use (Weingart, 2005a).

Future directions of the framework presented in this study can include assigning weights to indicators using CIDI methodology (Dobrota et al., 2015a; 2015b). Further, sensitivity and uncertainty analysis can be carried out in order to get a complete evaluation of the indicators that make the proposed framework. Besides altering the aggregation method and revising the number of selected indicators, there are several topics that should be elaborated if the framework is used on the global level.

First, researchers should not be misled by observing single bibliometrics indicators such as Number of papers or Average impact factor of the journal in which the papers appeared. In bibliometrics, quantity does not guarantee quality. Weingart (2005b) notes that in the time of evaluation-based funding scientists are taking a turn towards publishing more mainstream papers, which have less risk not to be published. In addition, Weingart points out that scholars tend to publish more in journals with lower impact, as long as the journal is indexed in citation indexes. Increasing rates of production raise the question whether the idea of maintaining a high level of quality over quantity has been forsaken (Costas; Van-Leeuwen; Bordons, 2010).

Attention should be placed to the disciplinary differences in citation patterns. Citation potential can significantly vary depending on the field analyzed; therefore, interdisciplinary comparison is improper. Field-specific differences in citing have been acknowledged more than thirty-five years ago, at the early stages of bibliometrics as a scientific field (Garfield, 1979). Therefore, percentiles and percentile-based indicators are recommended as a mean to overcome the observed differences and compare the impact of publications from different scientific fields. Also, percentiles can be used to get an in-depth analysis of certain groups of institutions within universities.

Lately, a growth trend has appeared in the number of authors per paper (Persson; Glänzel; Danell, 2004) and the level of international collaboration (Glänzel; Schubert, 2005). Citation behavior and values of bibliometric indicators of co-authored papers should be closely inspected. Disciplines in which such papers play an important role are high energy physics and biomedicine (Cronin, 2001). Some of the visible consequences of these two trends on citations are the decline of uncited papers, the increase of "average citation rate" and the increase of medium and highly cited papers (Persson; Glänzel; Danell, 2004). Thus, future scientometricians are advised to take this trend of increasing number of authors (from different countries) into account. The example provided showed thought-provoking results when only papers in which the leading author is from a particular faculty were considered.

As a follow-up of this study, it would be interesting to see how the ranking of the $U B$ faculties will change in the next four-year period, from 2012 to 2015. Furthermore, private universities that have lately emerged in Serbia might be considered. In the midst of higher education budget re-allocation and doctoral thesis plagiarism affairs (The Australian, 2014) a comparison of academic and scientific performance between state-owned and privately owned universities might be an interesting topic for various stakeholders. In addition, a more in-depth analysis of inter-institutional collaborations within the $U B$ might follow.

The proposed theoretical background of the framework and its later application on a university provides detailed insight into the performance of university's institutions. The results are useful to students, academia, and policy makers in decision-making. Hopefully, this study might trigger more research based on the framework.

\section{Acknowledgements}

The percentile-based indicators are from a bibliometric database developed and maintained by the Max Planck Digital Library (MPDL, Munich). The data are based on the Web of Science (Thomson Reuters, Philadelphia).

\section{Bibliography}

Abramo, Giovanni; Cicero, Tindaro; D’Angelo, Ciriaco-Andrea (2013). "The impact of unproductive and top researchers on overall university research performance". Journal of informetrics, v. 7, n. 1, pp. 166-175.

http://dx.doi.org/10.1016/j.joi.2012.10.006

Abramo, Giovanni; D’Angelo, Ciriaco-Andrea; Pugini, Fabio (2008). "The measurement of Italian universities' research productivity by a non parametric-bibliometric methodology". Scientometrics, v. 76, n. 2, pp. 225-244.

http://dx.doi.org/10.1007/s11192-007-1942-2

Acuña, Eduardo; Espinosa, Miguel; Cancino, Jorge (2013). "Paper-based productivity ranking of Chilean forestry institutions". Bosque, v. 34 n. 2, pp. 211-219.

http://dx.doi.org/10.4067/S0717-92002013000200010

Altanopoulou, Panagiota; Dontsidou, Maria; Tselios, Nikolaos (2012) "Evaluation of ninety-three major Greek university departments using Google Scholar". Quality in higher education, v. 18, n. 1, pp. 111-137.

http://dx.doi.org/10.1080/13538322.2012.670918

Altbach, Philip (2013). The international imperative in higher education. Rotterdam: SensePublishers. ISBN: 978 9462093379

ARWU (2014). "ARWU 2014-Methodology". Academic Ranking of World Universities.

http://www.shanghairanking.com/ARWU-Methodology-2014. html

Barnett, Bryan (1992). "Teaching and research are inescapably incompatible". The chronicle of higher education, $v$. 38, n. 40. 
Bornmann, Lutz (2013). "How to analyze percentile impact data meaningfully in bibliometrics? The statistical analysis of distributions, percentile rank classes, and top-cited papers". Journal of the Association for Information Science and Technology, v. 64, n. 3, pp. 587-595.

http://dx.doi.org/10.1002/asi.22792

Bornmann, Lutz; Bowman, Benjamin F.; Bauer, Johann; Marx, Werner; Schier, Hermann; Palzenberger, Margit (2014). "Bibliometric standards for evaluating research institutes in the natural sciences". In: Cronin, Blaise; Sugimoto, Cassidy R. (eds.) (2014). Beyond bibliometrics. Massachusetts Institute of Technology, pp. 201-224. ISBN: 97802625255510

Bornmann, Lutz; De-Moya-Anegón, Félix; Mutz, Rüdiger (2013). "Do universities or research institutions with a specific subject profile have an advantage or a disadvantage in institutional rankings?". Journal of the Association for Information Science and Technology, v. 64, n. 11, pp. 2310-2316. http://dx.doi.org/10.1002/asi.22923

Bornmann, Lutz; Leydesdorff, Loet; Mutz, Rüdiger (2013). "The use of percentiles and percentile rank classes in the analysis of bibliometric data: opportunities and limits". Journal of informetrics, v. 7, n. 1, pp. 158-165.

http://arxiv.org/abs/1211.0381

http://dx.doi.org/10.1016/j.joi.2012.10.001

Bornmann, Lutz; Leydesdorff, Loet; Wang, Jian (2013). "Which percentile-based approach should be preferred for calculating normalized citation impact values? An empirical comparison of five approaches including a newly developed citation-rank approach (P100)". Journal of informetrics, v. 7, n. 4, pp. 933-944. http://arxiv.org/abs/1306.4454 http://dx.doi.org/10.1016/j.joi.2013.09.003

Bornmann, Lutz; Marx, Werner (2014). "How to evaluate individual researchers working in the natural and life sciences meaningfully? A proposal of methods based on percentiles of citations". Scientometrics, v. 98, n. 1, pp. 487-509. http://arxiv.org/pdf/1302.3697.pdf http://dx.doi.org/10.1007/s11192-013-1161-y

Bornmann, Lutz; Mutz, Rüdiger (2011). "Further steps towards an ideal method of measuring citation performance: The avoidance of citation (ratio) averages in field-normalization". Journal of informetrics, v. 5, n. 1, pp. 228-230. http://www.lutz-bornmann.de/icons/AverageValue.pdf http://dx.doi.org/10.1016/j.joi.2010.10.009

Bornmann, Lutz; Mutz, Rüdiger (2014). “From P100 to P100': A new citation-rank approach". Journal of the American Society for Information Science and Technology, v. 65, n. 2, pp. 1939-1943.

http://dx.doi.org/10.1002/asi.23152

Bowman, Nicholas; Bastedo, Michael (2011). "Anchoring effects in world university rankings: exploring biases in reputation scores". Higher education, v. 61, n. 4, pp. 431-444. http://dx.doi.org/10.1007/s10734-010-9339-1

Brew, Angela; Boud, David (1995). "Teaching and research: Establishing the vital link with learning". Higher education, v. 29 , n. 3, pp. 261-273.

http://dx.doi.org/10.1007/BF01384493
Charles, David; Kitagawa, Fumi; Uyarra, Elvira (2014). “Universities in crisis? New challenges and strategies in two English city-regions". Cambridge journal of regions, economy and society, v. 7, n. 2, pp. 327-348.

http://dx.doi.org/10.1093/cjres/rst029

Chinchilla-Rodríguez, Zaida; Arencibia-Jorge, Ricardo; DeMoya-Anegón, Félix; Corera-Álvarez, Elena (2015a) "Somes patterns of Cuban scientific publication in Scopus: the current situation and challenges". Scientometrics, v. 103, n. 3, pp. 779-794 (in press.)

http://digital.csic.es/handle/10261/115267

http://dx.doi.org/10.1007/s11192-015-1568-8

Chinchilla-Rodríguez, Zaida; Zacca-González, Grisel; Vargas-Quesada, Benjamín; De-Moya-Anegón, Félix (2015b). "Latin American scientific output in public health: combined analysis using bibliometric, socioeconomic and health indicators". Scientometrics, v. 102, n. 1, pp. 609-628.

http://digital.csic.es/handle/10261/108463?locale =es

http://dx.doi.org/10.1007/s11192-014-1349-9

Chou, Chuing-Prudence; Lin, Hsiao-Fang; Chiu, Yun-ju (2013). "The impact of SSCl and SCl on Taiwan's academy: an outcry for fair play". Asia Pacific education review, v. 14, n. 1, pp. 23-31.

http://goo.gl/45cHLL

http://dx.doi.org/10.1007/s12564-013-9245-1

Costas, Rodrigo; Van-Leeuwen, Thed N.; Bordons, María (2010). "A bibliometric classificatory approach for the study and assessment of research performance at the individual level: The effects of age on productivity and impact". Journal of the American Society for Information Science and Technology, v. 61, n. 8, pp. 1564-1581.

http://dx.doi.org/10.1002/asi.21348

Cronin, Blaise (2001). "Hyperauthorship: A postmodern perversion or evidence of a structural shift in scholarly communication practices?". Journal of the American Society for Information Science and Technology, v. 52, n. 7, pp. 558-569. http://dx.doi.org/10.1002/asi.1097

Dobrota, Marina; Bulajic, Milica; Bornmann, Lutz; Jeremic, Veljko (2015a). "A new approach to QS University Ranking using composite I-distance indicator: uncertainty and sensitivity analyses". Journal of the Association for Information Science and Technology. In press.

http://dx.doi.org/10.1002/asi.23355

Dobrota, Marina; Martic, Milan; Bulajic, Milica; Jeremic, Veljko (2015b). "Two-phased composite I-distance indicator approach for evaluation of countries' information development". Telecommunications policy, v. 39, n. 5, pp. 406-420. http://dx.doi.org/10.1016/j.telpol.2015.03.003

Docampo, Domingo (2013). "Reproducibility of the Shanghai academic ranking of world universities". Scientometrics, v. 94, n. 2, pp. 567-587.

http://dx.doi.org/10.1007/s11192-012-0801-y

Etzkowitz, Henry (1998). "The norms of entrepreneurial science: cognitive effects of the new university-industry linkages". Research policy, v. 27, n. 8, pp. 823-833. http://dx.doi.org/10.1016/S0048-7333(98)00093-6 
Frey, Bruno S. (2003). "Publishing as prostitution? Choosing between one's own ideas and academic success". Public choice, v. 116, n. 1-2, pp. 205-223.

http://www.bsfrey.ch/articles/388_03.pdf

http://dx.doi.org/10.1023/A:1024208701874

Gálvez, Carmen; De-Moya-Anegón, Félix (2006). “The unification of institutional addresses applying parametrized finitestate graphs (P-FSG)". Scientometrics, v. 69, n. 2, pp. 323-345. http://eprints.rclis.org/10019/

http://dx.doi.org/10.1007/s11192-006-0156-3

Garfield, Eugene (1979). "Is citation analysis a legitimate evaluation tool?". Scientometrics, v. 1, n. 4, pp. 359-375. http://dx.doi.org/10.1007/BF02019306

Geuna, Aldo; Martin, Ben R. (2003). "University research evaluation and funding: An international comparison". Minerva, v. 41, n. 4, pp. 277-304.

http://dx.doi.org/10.1023/B:MINE.0000005155.70870.bd

Glänzel, Wolfgang; Schubert, András (2005). “Analysing scientific networks through co-authorship". In: Moed, Henk; Glänzel, Wolfgang; Schmoch, Ulrich. Handbook of quantitative science and technology research. Springer Netherlands, pp. 257-276. ISBN: 9781402027550

Gulbrandsen, Magnus; Smeby, Jens-Christian (2005). "Industry funding and university professors' research performance". Research policy, v. 34, n. 6, pp. 932-950.

http://dx.doi.org/10.1016/j.respol.2005.05.004

Hazelkorn, Ellen (2007). "The impact of league tables and ranking systems on higher education decision making". Higher education management and policy, v. 19, n. 2, pp. 87-110. http://dx.doi.org/10.1787/hemp-v19-art12-en

Hazelkorn, Ellen (2011). Rankings and the reshaping of higher education. The battle for world-class excellence. New York: Palgrave Macmillan. ISBN: 023024324X

Hazelkorn, Ellen (2014). "Reflections on a decade of global rankings: what we've learned and outstanding issues". European journal of education, v. 49, n. 1, pp. 12-28.

http://arrow.dit.ie/cgi/viewcontent.cgi?article $=1046 \&$ conte $x t=c s e r a r t$

http://dx.doi.org/10.1111/ejed.12059

Hazen, Allen (1914). "Storage to be provided in impounding reservoirs for municipal water supply". Transactions of American Society of Civil Engineers, v. 77, pp. 1539-1640.

Heck, Ronald; Lam, Wendy; Thomas, Scott (2014). "State political culture, higher education spending indicators, and undergraduate graduation outcomes". Educational policy, v. 28, n. 1, pp. 3-39.

http://dx.doi.org/10.1177/0895904812453996

Hicks, Diana; Wouters, Paul; Waltman, Ludo; De-Rijcke, Sarah; Rafols, Ismael (2015). "The Leiden Manifesto for research metrics". Nature, v. 520, n. 7548, pp. 429-431.

http://dx.doi.org/10.1038/520429a

Hintze, Jerry L.; Nelson, Ray D. (1998). "Violin plots: A box plot-density trace synergism". The American Statistician, v. 52, n. 2, pp. 181-184.

https://quantixed.files.wordpress.com/2014/12/hintze_1998.pdf http://dx.doi.org/10.1080/00031305.1998.10480559

Horstschräer, Julia (2012). "University rankings in action? The importance of rankings and an excellence competition for university choice of high-ability students". Economics of education review, v. 31, n. 6, pp. 1162-1176.

http://dx.doi.org/10.1016/j.econedurev.2012.07.018

Hurtado, Sylvia; Eagan, M. Kevin; Tran, Minh C.; Newman, Christopher B.; Chang, Mitchell J.; Velasco, Paolo (2011). “'We do science here': Underrepresented students' interactions with faculty in different college contexts". Journal of social issues, v. 67, n. 3, pp. 553-579.

http://dx.doi.org/10.1111/j.1540-4560.2011.01714.x

Ivanovic, Branislav (1977). Classification theory. Belgrade: Institute for Industrial Economics.

Ivanovic, Dragan; Ho, Yuh-Shan (2014). "Independent publications from Serbia in the Science Citation Index Expanded: a bibliometric analysis". Scientometrics, v. 101, n. 1, pp. 603-622. http://dx.doi.org/10.1007/s11192-014-1396-2

Jain, Sanjay; George, Gerard; Maltarich, Mark (2009). “Academics or entrepreneurs? Investigating role identity modification of university scientists involved in commercialization activity". Research policy, v. 38, n. 6, pp. 922-935.

http://dx.doi.org/10.1016/j.respol.2009.02.007

Jeremic, Veljko; Bulajic, Milica; Martic, Milan; Radojicic Zoran (2011). "A fresh approach to evaluating the academic ranking of world universities". Scientometrics, v. 87, n. 3, pp. 587-596.

http://dx.doi.org/10.1007/s11192-011-0361-6

Jeremic, Veljko; Jovanovic-Milenkovic, Marina; Radojicic, Zoran; Martic, Milan (2013). "Excellence with Leadership: the crown indicator of SCImago Institutions Rankings Iber report". El profesional de la información, v. 22, n. 5, pp. 474-480. http://dx.doi.org/10.3145/epi.2013.sep.13

Jovanovic, Milica; Jeremic, Veljko; Savic, Gordana; Bulajic, Milica; Martic, Milan (2012). "How does the normalization of data affect the ARWU ranking?". Scientometrics, v. 93, n. 2, pp. 319-327.

http://dx.doi.org/10.1007/s11192-012-0674-0

King, Jean (1987). "A review of bibliometric and other science indicators and their role in research evaluation". Journal of information science, v. 13, n. 5, pp. 261-276. http://dx.doi.org/10.1177/016555158701300501

Leydesdorff, Loet (2007). "Caveats for the use of citation indicators in research and journal evaluations". Journal of the American Society for Information Science and Technology, v. 59, n. 2, pp. 278-287.

http://onlinelibrary.wiley.com/doi/10.1002/asi.20743/epdf http://dx.doi.org/10.1002/asi.20743

Leydesdorff, Loet; Bornmann, Lutz (2011). “How fractional counting of citations affects the impact factor: Normalization in terms of differences in citation potentials among fields of science". Journal of the American Society for Information Science and Technology, v. 62, n. 2, pp. 217-229. http://arxiv.org/abs/1007.4749 http://dx.doi.org/10.1002/asi.21450 
Leydesdorff, Loet; Bornmann, Lutz; Mutz, Rüdiger; Opthof, Tobias (2011). "Turning the tables in citation analysis one more time: Principles for comparing sets of documents". Journal of Association for Information Science and Technology, v. 62, n. 7, pp. 1370-1381.

http://arxiv.org/abs/1101.3863

http://dx.doi.org/10.1002/asi.21534

Marope, Mmantsetsa; Wells, Peter; Hazelkorn, Ellen (2013). Rankings and accountability in higher education: Uses and misuses. Paris: Unesco. ISBN: 9789230111567 http://unesdoc.unesco.org/images/0022/002207/220789e.pdf

McGrail, Matthew R.; Rickard, Claire M.; Jones, Rebecca (2006). "Publish or perish: a systematic review of interventions to increase academic publication rates". Higher education research \& development, v. 25, n.1, pp. 19-35.

https://www.tcd.ie/wiser/development/writing-group/ documents/McGrail-et-al-2006.pdf

http://dx.doi.org/10.1080/07294360500453053

Melin, Göran; Persson, Olle (1996). "Studying research coIlaboration using co-authorships". Scientometrics, v. 36, n. 3, pp. 363-377.

http://federation.edu.au/_data/assets/pdf_file/0003/221268/14melin.pdf

http://dx.doi.org/10.1007/BF02129600

Moed, Henk F. (2002). "The impact factors debate: The ISI's uses and limits". Nature, v. 415, pp. 731-732.

http://dx.doi.org/10.1038/415731a

Moed, Henk F.; Burger, W. J. M.; Frankfort, J. G.; Van-Raan, Anthony F. J. (1985). "The use of bibliometric data for the measurement of university research performance". Research policy, v. 14, n. 3, pp. 131-149.

http://dx.doi.org/10.1016/0048-7333(85)90012-5

National Science Board (2012). Science and engineering indicators 2012. Arlington, VA, USA: National Science Foundation (NSB 12-01).

Paruolo, Paolo; Saisana, Michaela; Saltelli, Andrea (2013). "Ratings and rankings: voodoo or science?". Journal of the Royal Statistical Society: Series A (Statistics in society), v. 176, n. 3, pp. 609-634.

http://arxiv.org/pdf/1104.3009.pdf

http://dx.doi.org/10.1111/j.1467-985X.2012.01059.x

Persson, Olle; Glänzel, Wolfgang; Danell, Rickard (2004). "Inflationary bibliometric values: The role of scientific collaboration and the need for relative indicators in evaluative studies". Scientometrics, v. 60, n. 3, pp. 421-432. http://dx.doi.org/10.1023/B:SCIE.0000034384.35498.7d

Price, Jammie; Cotten, Shelia R. (2006). "Teaching, research, and service: Expectations of assistant professors". The American sociologist, v. 37, n. 1, pp. 5-21.

http://dx.doi.org/10.1007/s12108-006-1011-y

Radojicic, Zoran; Jeremic, Veljko (2012). “Quantity or quality: what matters more in ranking higher education institutions?". Current science, v. 103, n. 2, pp. 158-162 http://www.currentscience.ac.in/Volumes/103/02/0158. $p d f$
Rauhvargers, Andrejs (2013). Global university rankings and their impact. Report II. Brussels, Belgium: European University Association (EUA). ISBN: 9789078997412

http://www.eua.be/Libraries/Publications_homepage_list/ EUA_Global_University_Rankings_and_Their_Impact_-Report_Il.sflb.ashx

Reale, Emanuela; Primeri, Emilia (2014). "Reforming universities in Italy: Towards a new paradigm?". Reforming higher education, v. 41, pp. 39-63.

http://dx.doi.org/10.1007/978-94-007-7028-7_3

Rehn, Catharina; Kronman, Ulf; Wadskog, Daniel (2007). Bibliometric indicators. Definitions and usage at Karolinska Institutet. Stockholm, Sweden: Karolinska Institutet University Library.

Saisana, Michaela; D’Hombres, Beatrice (2008). Higher education rankings: Robustness issues and critical assessment; How much confidence can we have in higher education rankings? Luxembourg: Joint Research Centre. ISBN: 9788279097041

https://globalhighered.files.wordpress.com/2008/11/ eur23487.pdf

Saisana, Michaela; D’Hombres, Beatrice; Saltelli, Andrea (2011). "Rickety numbers: Volatility of university rankings and policy implications". Research policy, v. 40, n. 1, pp. 165-177. http://dx.doi.org/10.1016/j.respol.2010.09.003

Tang, Li; Walsh, John P. (2010). "Bibliometric fingerprints: name disambiguation based on approximate structure equivalence of cognitive maps". Scientometrics, v. 84, n. 3, pp. 763-784.

https://www.thevantagepoint.com/resources/articles/ TangWalsh-scientometrics-online.pdf

http://dx.doi.org/10.1007/s11192-010-0196-6

The Australian (2014). “Bogus academic claims tarnish Serbia's ivory tower". The Australian. Higher education, June 30.

http://goo.gl/QviDAU

Thomson Reuters (2014). Web of Knowledge. https://webofknowledge.com

University of Belgrade (2014). Faculties http://www.bg.ac.rs/en/members/faculties/faculties.php

Van-Raan, Anthony F. J. (2003). "The use of bibliometric analysis in research performance assessment and monitoring of interdisciplinary scientific developments". Technikfolgenabschätzung - Theorie und praxis, v. 1, n. 12, pp. 20-29. http://www.cwts.nl/TvR/documents/AvR-TFA2003.pdf

Van-Raan, Anthony F. J. (2005). "For your citations only? Hot topics in bibliometric analysis". Measurement: Interdisciplinary research and perspectives, v. 3, n. 1, pp. 50-62. http://www.cwts.nl/TvR/documents/AvR-ForYourCit.pdf http://dx.doi.org/10.1207/s15366359mea0301_7

Waltman, Ludo; Calero-Medina, Clara; Kosten, Joost; Noyons, Ed; Tijssen, Robert J. W.; Van-Eck, Nees-Jan; VanLeeuwen, Thed N.; Van-Raan, Anthony F. J.; Visser, Martijn S.; Wouters, Paul (2012). "The Leiden Ranking 2011/2012: Data collection, indicators, and interpretation". Journal of the American Society for Information Science and Technology, v. 63, n. 12, pp 2419-2432. 
http://arxiv.org/abs/1202.3941

http://dx.doi.org/10.1002/asi.22708

Waltman, Ludo; Schreiber, Michael (2013). “On the calculation of percentile-based bibliometric indicators". Journal of the American Society for Information Science and Technology, v. 64, n. 2, pp. 372-379.

http://arxiv.org/pdf/1205.0646.pdf

http://dx.doi.org/10.1002/asi.22775

Waltman, Ludo; Van-Eck, Nees-Jan; Van-Leeuwen, Thed N.; Visser, Martijn S.; Van-Raan, Anthony F. J. (2011). "Towards a new crown indicator: Some theoretical considerations". Journal of informetrics, v. 5, n. 1, pp. 37-47.

http://arxiv.org/pdf/1003.2167.pdf

http://dx.doi.org/10.1016/j.joi.2010.08.001

Weingart, Peter (2005a). "Das ritual der evaluierung und die verführbarkeit". In: Weingart, P. (Ed.). Die wissenschaft der öffentlichkeit: Essays zum verhältnis von wissenschaft,
Medien und öffentlichkeit. Weilerswist, Germany, Velbrück, pp. 102-122. ISBN: 9783934730038

Weingart, Peter (2005b). "Impact of bibliometrics upon the science system: Inadvertent consequences?". Scientometrics, v. 62, n. 1, pp. 117-131. http://dx.doi.org/10.1007/s11192-005-0007-7

Zhou, Ping; Leydesdorff, Loet (2011). "Fractional counting of citations in research evaluation: A cross-and interdisciplinary assessment of the Tsinghua University in Beijing". Journal of informetrics, v. 5, n. 3, pp. 360-368 (2011).

http://dx.doi.org/10.1016/j.joi.2011.01.010

Zornic, Nikola; Markovic, Aleksandar; Jeremic, Veljko (2014). "How the Top 500 ARWU can provide a misleading rank". Journal of Association for Information Science and Technology, v. 65, n. 6, pp. 1303-1304.

http://dx.doi.org/10.1002/asi.23207

\section{INFORMES THINKEPI 2015 SOBRE DOCUMENTACIÓN Y COMUNICACIÓN}

Baiget, Tomàs (dir); Olea, Isabel (coord.) (2015). Informes ThinkEPI 2015. 17x24 cm. Barcelona: Editorial EPI, 213 pp. ISBN: 9788460682097

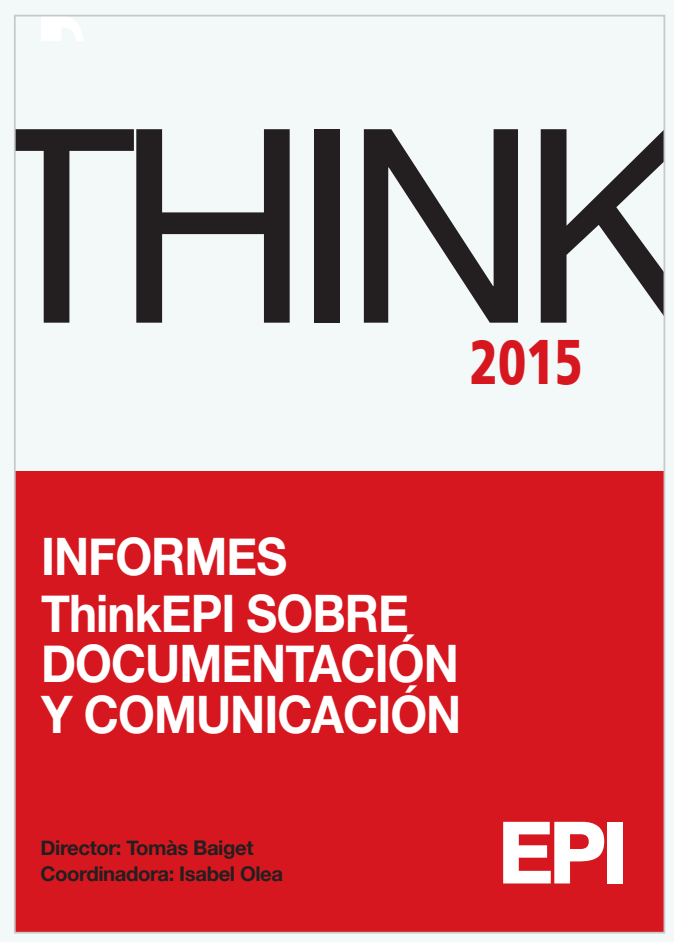

Pedidos: Isabel Olea

epi.iolea@gmail.com
Prólogo: La gran disrupción: la Web + los dispositivos móviles y lo que podemos hacer

\section{Lluís Codina}

Bibliotecas virtuales en 2014, año de consolidación del modelo linked open data

Xavier Agenjo-Bullón

Tecnología móvil y bibliotecas en 2014: ampliando el concepto de movilidad

\section{Natalia Arroyo-Vázquez}

Encuesta internacional de automatización de bibliotecas Marshall Breeding

Moocs: estado actual, retos y oportunidades Josep Cobarsí-Morales

Los libros electrónicos: principales tendencias y prospectiva José-Antonio Cordón-García

Servicios de suscripción de libros electrónicos: modelos y tendencias

José-Antonio Cordón-García

Comunicación científica en 2014. En torno a la 'altmetría' Rodrigo Costas

Informe de la situación de los medios sociales en el sector de la información y la documentación en 2014 y prospectiva 2015 Nieves González-Fernández-Villavicencio

Medios de comunicación digitales en 2014: un balance alternativo

Pere Masip

Acceso abierto en 2014: se sigue avanzando

Remedios Melero y Ernest Abadal

Web semántica. Informe de situación 2014

Juan-Antonio Pastor-Sánchez y Tomás Saorín

Resumen de actividades de IFLA, Eblida, Liber y Fesabid en 2014

Glòria Pérez-Salmerón

Informe de situación 2015: profesión y formación universitaria Carlos-Miguel Tejada-Artigas 